\title{
Patterns of failure after brain metastases radiotherapy: reflections on the importance for treatment and clinical trials reporting
}

\author{
Minireview
}

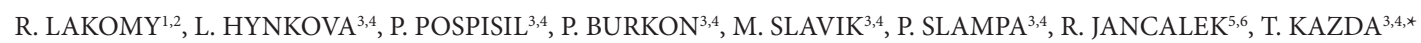

${ }^{1}$ Department of Comprehensive Cancer Care, Masaryk Memorial Cancer Institute, 65653 Brno, Czech Republic; ${ }^{2}$ Department of Comprehensive Cancer Care, Faculty of Medicine, Masaryk University, 62500 Brno, Czech Republic; ${ }^{3}$ Department of Radiation Oncology, Masaryk Memorial Cancer Institute, Zluty kopec 7, 65653 Brno, Czech Republic; ${ }^{4}$ Department of Radiation Oncology, Faculty of Medicine, Masaryk University, Kamenice 5, 62500 Brno, Czech Republic; ${ }^{5}$ Department of Neurosurgery, St. Anne's University Hospital Brno, Faculty of Medicine, Masaryk University, 62500 Brno, Czech Republic; ${ }^{6}$ Department of Neurosurgery, St. Anne’s University Hospital Brno, 65691 Brno, Czech Republic

*Correspondence: tomas.kazda@mou.cz

Received September 20, 2016 / Accepted December 19, 2016

\begin{abstract}
In many ongoing clinical trials, new strategies for radiotherapy of brain metastases are currently being investigated. A post surgical focal cavity stereotactic radiosurgery and the developing role of a hippocampal-sparing whole brain radiotherapy are of the highest importance. The evaluation of spatial patterns of metastases failure after radiotherapy is a powerful tool for assessing the potential benefit of new different radiotherapy approaches, which enables to identify possible directions leading to better radiotherapy techniques and to modify general management for newly diagnosed brain metastases. The purpose of this article is to present a mix between trial data and philosophical point of view for discussion about the importance of systematic evaluation of spatial patterns of failure in all ongoing trials investigating new approaches in local brain metastases treatment.
\end{abstract}

Key words: progression, brain recurrence, stereotactic radiosurgery, whole brain radiotherapy, hippocampal sparing radiotherapy

Up to $30 \%$ of all new solid cancer patients develop brain metastases (BM) and this condition is historically associated with a grim prognosis [1]. Radiotherapy has been the mainstay of their treatment for decades. Generally, the most important tumor-specific outcome of radiotherapy is local control compared to systemic treatment, where other outcomes may be of higher importance. Evaluation of spatial patterns of failure (PoF) after locally oriented treatment, as is the neurosurgery or stereotactic radiotherapy, is a powerful tool for assessing the potential benefit of new different radiotherapy or neurosurgery approaches. The purpose of this article is to present a mix between trial data and philosophical point of view for discussion about the importance of systematic evaluation of spatial PoF in all ongoing trials investigating new approaches in local BM treatment. Not only in local treatment, the PoF evaluation may also be valuable in studies focused on advanced whole-brain-radiotherapy (WBRT) techniques as is the topical concept of hippocampal avoidance [2].

Currently, an international multidisciplinary working group, known as The Response Assessment in Neuro-Oncology Brain Metastases (RANO-BM), developed standard response and progression criteria for usage in clinical trials which are investigating the treatment of BM [3]. This new guidelines already prooved the importance of the PoF for robust assessment of future trials. This importance was already validated in primary brain tumors radiotherapy, when Minniti et al. compared two most common contouring approaches in high grade gliomas - the former by Radiation Therapy Oncology Group (RTOG) and the latter by European Organisation for Research and Treatment of Cancer (EORTC). A similar proportion of PoF (recurrence within the high dose field) has been reported which may support the EORTC-derived con- 
touring approach with an absolute smaller volume of irradiated brain [4]. Indeed, current studies evaluating new contouring strategies for gliomas include a protocol-specified $\mathrm{PoF}$ analysis [5]. Is it also possible to translate the PoF analysis of BM into similar clinical utility?

\section{Patterns of failure after neurosurgery \pm WBRT}

For decades, WBRT has been the most common technique used for the treatment of BM. It is simple, cheap and available in all radiotherapy departments including low income countries. There are also other cancer-related factors which support the indication of WBRT in comparison to other radiotherapy approaches - especially the number and size of metastases and pattern of metastatic spread as a biology feature of some primary cancers. On the other hand, patients with limited number of BM should be considered for more local treatment, such as neurosurgery or stereotactic radiosurgery (SRS) or stereotactic fractionated radiotherapy. In this paragraph, we discus surgical resection, which is considered standard care for solitary metastasis larger than $3 \mathrm{~cm}$ and in noneloquent areas of the brain assuming limited and/or controlled systemic disease and good performance status (Karnofsky performance status $>70 \%)$. Generally, neurosurgery is reserved for patients with good prognosis (expected survival 3 months or more). Resection of BM is individually indicated, especially where the neurological deficit caused by large MTS seems to be reversible after the tumor removal [6], [7]. Currently, more attention is paid to the investigation of combined approaches since the PoF analysis after surgery alone reveals an unsatisfactory local control as discussed further.

In one of the pioneer studies investigating the addition of WBRT to resection of BM, local recurrence on the site of the original metastasis developed in almost $50 \%$ of those undergoing neurosurgery alone (21 of 46 patients), comparing to $10 \%$ when WBRT was added postoperatively ( 5 of 49 patients) [8]. In this randomized prospective trial by Patchell et al., all patients underwent complete surgical resection of their single brain metastasis and were subsequently assigned to get WBRT or observation. Not only recurrences on the original site, but also at the other site of brain were less frequent in the WBRT arm (primary endpoint - recurrence of tumor in the brain). Nevertheless, no difference in survival was found using surgery plus WBRT versus surgery alone, although the study was not powered for survival estimations (a secondary endpoint of this trial). Despite the fact that there was no difference in overall survival, patients in the radiotherapy group died less likely for neurologic reasons [8]. For many physicians, this decrease in the risk of neurological death is a sufficient reason to include upfront WBRT into their treatment recommendation since neurological death (with serious loss of both mental and physical abilities) is considered to be one of the most serious types of death for both the patient, and his or her family and caregivers to deal with [9]. On the other hand, protocol dosage of WBRT with 50.4 Gy delivered in 28 fractions [8] is exces- sively high from the current point of view similarly as attending radiotherapy department for 5.5 weeks is not consistent with principles of palliative treatment. Nevertheless, analysis of $\mathrm{PoF}$ after BM resection is still an important outcome in further development of postsurgery treatment.

There are more retrospective studies that evaluate PoF after surgical resection \pm WBRT of single brain metastasis. In 2007 , Nieder et al. [10] provided a summary of results from 10 relevant trials. A combined analysis of PoF for pooled 643 patients revealed significant decrease in the development of local relapse on the original site in patients with postsurgical radiotherapy (local relapse in $40 \%$ non-irradiated patients vs. $12,5 \%$ patients with WBRT; $\mathrm{p}<0,01$ ) [10]. More recently - in March 2014, a cochrane review focused on randomized trials comparing surgery or SRS alone versus surgery or SRS plus WBRT was published by Soon et al. [11]. In addition to an improved local control, the PoF evaluation also confirmed decreased risk of progression on any site of brain when upfront WBRT is added. On the other hand, there was no difference in overall survival; and the benefit of adding WBRT to local treatment in terms of quality of life remains unclear.

The value of adding WBRT to local treatment (surgery of SRS), including quality of life aspects, was evaluated in 2011 within the pioneer EORTC 22952-26001 study by Kocher et al. [12]. The omission of WBRT did not increase the proportion of patients whose performance status got worse by 2 points and more (the loss of functional independence). The PoF analysis confirmed other, while anticipated, findings: the main site of failure for patients treated with surgery only was surgical cavity (59\%; 95\% confidence interval: $48 \%$ to $71 \%$ ). WBRT reduced the probability of the relapse in surgical bed to $27 \%$ (95\% CI: $31 \%$ to $53 \%, \mathrm{p}<0.001)$. Moreover, failures on the new sites in the brain with surgery alone reached $42 \%$ (95\% CI: $31 \%$ to $53 \%$ ), with WBRT reducing these events to $23 \%$ (95\% CI: $14 \%$ to $33 \%, p=0.008$ ) [12]. These results showed what may be the value of WBRT in the lack of survival benefit, which is seen in unselected population of patients with BM.

With no change in survival, upfront postresection WBRT might be considered overtreatment. Nevertheless, the survival improvement itself may no longer be the main interest of treating physicians when having a patient with $\mathrm{BM}$. In recent ongoing trials focusing on the treatment of brain tumors, QoL and cognitive function are more often considered a primary study outcome [13]. Considering the palliative intent of the treatment of patients with $\mathrm{BM}$, a simple prolongation of survival with continuous functional deterioration is not clinically meaningful and postsurgical WBRT even in absence of survival improvement may be judged.

Many questions regarding the postsurgery WBRT remain unanswered. Is the decrease in risk of neurological death worth the adverse effects of WBRT affecting both the quality of life (QoL) and neurocognition? An assessment of a battery of validated neurocognitive tests is crucial for minimizing these adverse effects of WBRT [14]. Nonetheless, Aoyama et al. suggest that consequences of cognitive impairment following 
intracranial failure are worse than consequences of WBRT [15]. Considering, that candidates for resection of BM are generally patients in a good condition, preservation of their QoL and neurocognition is of high importance so they deserve some adjuvant treatment.

\section{Patterns of failure after focal cavity radiosurgery}

New strategies of improving local control after surgery of $\mathrm{BM}$ without the risk of WBRT-associated cognitive effects have recently beed investigated. The focal instead of the whole brain irradiation was recognized as a promising approach to increase local control after the surgical removal of BM. It can be assumed that the highest risk of failure is on the original site - that is in the region where already present cancer cells found favorable conditions for seeding. Thus, stereotactic fractionated radiotherapy or single fraction SRS targeted to postresection cavity can assure both improvement in local control, and postponement or even omission of WBRT, with its possible neurocognitive sequelae. Spatial PoF after this treatment strategy may reveal its superiority in comparison to other approaches including observation or WBRT. Many examples of retrospective single institution experience have been published so far, confirming the feasibility and low toxicity of postsurgery resection cavity irradiation using the gamma knife [16] or the frame less linear accelerator-based SRS [17] [18]. Nevertheless, only well designed prospective randomized trials can probably definitely solve all related ambiguity [19].

RTOG 1270/NCCTG N107C is an ongoing randomized phase III clinical trial comparing SRS with WBRT in the treatment of patients with one to four brain metastases that have been removed by surgery. Co-primary objectives are the overall survival and the time to neurocognitive progression, while spatial PoF (local, distant, or leptomeningeal) together with the QoL and other toxicity reports are secondary outcomes. Another recruiting investigational phase III clinical trial NCI-2011-00542 directed by M.D. Anderson Cancer Center compares postsurgical cavity SRS with observation by regular magnetic resonance imaging. The primary outcome is the time to local recurrence and the final data collection will be estimated in mid-2017. The PoF analyses of these two trials will also contribute to the debate on the relevance of adjuvant WBRT.

Many technical and radiotherapy treatment planning issues also need to be standardized in order to validly compare results, especially PoF. Different timing of SRS after surgery can affect the volume of radiation target, because surgical cavities are dynamic in size. The detailed analysis of MRI from 41 patients undergoing post-surgery cavity SRS revealed that nearly one third of cavities enlarged and one quarter collapsed compared to post-surgery MRI findings obtained immediately after the surgery [20]. The greatest change in volume seems to occur early after surgery and there is no benefit in waiting longer than the first one to two weeks for possible cavity shrinking [21]. The final treatment volume is also influenced by additional margins to resection cavity, which also affect the local control in the end. Comparing to gliomas, $\mathrm{BM}$ are considered as not-infiltrating, however, an expansion by $2 \mathrm{~mm}$ around cavity was correlated with the improvement in the local control and has become the standard approach [22]. The $\mathrm{PoF}$ analysis may be influenced by the non-uniform timing and strategy of surgical cavity SRS. For example, the recurrence in the region of decreasing radiation dose ("marginal") may be evaluated in the subsequent PoF analysis as "central" recurrence in the case where cavity would be continuously collapsing after radiotherapy.

The PoF after surgical cavity stereotactic radiotherapy are difficult to summarize because of the retrospective nature of data published so far, which are almost exclusively single institution experience. Generally speaking, a satisfactory local control is achieved with reported local failure in roughly 10 to $20 \%$, which is comparable to results reached by the adjuvant WBRT alone [23]. The benefit of WBRT postponement or even omission is counterbalanced by a decreased distant brain control [23]. Since the main motivation to replace WBRT by cavity SRS is preclusion of brain radiation injury associated with WBRT, a recent development of HA WBRT may compromise a potential wider usage of cavity SRS in the treatment protocols. The PoF evaluation in patients enrolled in phase III clinical trials mentioned above will provide useful data for future treatment recommendation. Other useful information for the future daily RT planning and targeting may be provided by a dosimetrically detailed analysis of PoF, for example a categorization based on the received dose within the relapse region. Table 1 summarizes prospective clinical trials investigating resection bed post-surgical radiotherapy, which are listed within U.S. National Institutes of Health database (clinicaltrials.gov, September 2016).

\section{Patterns of failure after radiosurgery \pm WBRT}

The continuous modernization of radiation oncology departments enable a wider usage of SRS or fractionated stereotactic radiotherapy systems. Even though recently published phase III trials show superiority of solely SRS for patients with brain oligometastases, some controversy remains over the indication of upfront SRS \pm WBRT, similarly to the case of the combination of neurosurgery and WBRT. The first prospective randomized multicenter phase III trial focusing on this combination was conducted in Japan by Aoyama et al. in 2006, where the primary endpoint was the difference in overall survival [15]. Patients with maximum of four metastases up to $3 \mathrm{~cm}$ were randomized to SRS \pm WBRT. No significant difference in the median survival or one year survival was reported, nor any difference in the death attributed to neurologic causes. Yet the trial was not designed as an equivalency study and should not be interpreted as such. Also, the study was now powered enough to draw any conclusion about cognitive differences between study arms. On the other hand, PoF revealed a lower 12 -month actuarial rate of all $\mathrm{BM}$ relapses in the combined 
Table 1. Summary of prospective clinical trials investigating resection bed post-surgical radiotherapy.

\begin{tabular}{|c|c|c|c|c|c|c|c|}
\hline Study name & CTG Identifier & Study status & $\begin{array}{l}\text { Study } \\
\text { phase }\end{array}$ & Intervention & $\begin{array}{l}\text { Estimated } \\
\text { enrollment }\end{array}$ & $\begin{array}{l}\text { PoF as an } \\
\text { outcome } \\
(\mathrm{P} / \mathrm{S} / \mathrm{NA})\end{array}$ & $\begin{array}{l}\text { NCF as an } \\
\text { outcome } \\
(\mathrm{P} / \mathrm{S} / \mathrm{NA})\end{array}$ \\
\hline $\begin{array}{l}\text { A Phase III Trial of Post-Surgical Stereotactic Radiosurgery } \\
\text { (SRS) Compared With Whole Brain Radiotherapy } \\
\text { (WBRT) for Resected Metastatic Brain Disease }\end{array}$ & NCT01372774 & $\begin{array}{l}\text { recruiting } \\
\text { participants }\end{array}$ & III & SRS vs.WBRT & 192 & $\mathrm{~S}$ & $\mathrm{P}$ \\
\hline $\begin{array}{l}\text { Phase } 3 \text { Study of Stereotactic Radiotherapy of the } \\
\text { Postoperative Resection Cavity Versus Whole-Brain } \\
\text { Irradiation After Surgical Resection of Single Brain } \\
\text { Metastasis }\end{array}$ & NCT01535209 & $\begin{array}{l}\text { unknown } \\
\text { (not verified } \\
\text { yet) }\end{array}$ & III & SRS vs.WBRT & 100 & $\mathrm{P}$ & NA \\
\hline $\begin{array}{l}\text { Efficacy of Post-Surgical Stereotactic Radiosurgery for } \\
\text { Metastatic Brain Disease: A Randomized Trial }\end{array}$ & NCT00950001 & $\begin{array}{l}\text { ongoing, but } \\
\text { not recruiting } \\
\text { participants }\end{array}$ & III & $\begin{array}{l}\text { SRS vs. } \\
\text { observation }\end{array}$ & 132 & $\mathrm{P}$ & NA \\
\hline $\begin{array}{l}\text { A Single Center Prospective Phase II Study: Stereotactic } \\
\text { Radiosurgery to the Resection Cavity Following Surgical } \\
\text { Removal of Brain Metastasis }\end{array}$ & NCT00484978 & $\begin{array}{l}\text { unknown } \\
\text { (not verified } \\
\text { yet) }\end{array}$ & II & SRS & 35 & $\mathrm{P}$ & NA \\
\hline $\begin{array}{l}\text { Tumor Bed Hypofractionated IMRT (VMAT-RA) } \\
\text { After Surgical Resection for Patients With Single, Large } \\
(\geq 2.1 \mathrm{~cm}) \text { Brain Metastases From Solid Tumor }\end{array}$ & NCT02576522 & $\begin{array}{l}\text { currently } \\
\text { recruiting } \\
\text { participants }\end{array}$ & II & SRS & 55 & $\mathrm{P}$ & S \\
\hline $\begin{array}{l}\text { Phase I Trial of Stereotactic Radiosurgery Following } \\
\text { Surgical Resection of Brain Metastases }\end{array}$ & NCT01395407 & completed & I & SRS & 9 & S & S \\
\hline $\begin{array}{l}\text { Pilot Study of Resection Combined With Stereotactic } \\
\text { Radiosurgery in Patients With Limited (1-3) Brain } \\
\text { Metastases }\end{array}$ & NCT00904553 & $\begin{array}{l}\text { ongoing, but } \\
\text { not recruiting } \\
\text { participants }\end{array}$ & pilot & SRS & 25 & $\mathrm{P}$ & $\mathrm{P}$ \\
\hline $\begin{array}{l}\text { Pilot Study of Adjuvant Fractionated Stereotactic } \\
\text { Radiotherapy Following Surgical Removal of Cerebral } \\
\text { Metastases }\end{array}$ & NCT00003320 & completed & pilot & SRS & 20 & $\mathrm{P}$ & NA \\
\hline
\end{tabular}

treatment ( $46.8 \%$ vs. $76.4 \%, \mathrm{p}<0.001)$, relapses in the region of original lesion ( $11.3 \%$ vs. $27.5 \%, \mathrm{p}=0.002)$, as well as the development of any new brain lesion ( $41.5 \%$ vs. $63.7 \%, \mathrm{p}=0.003)$. This observation is similar to that described in the comparison of neurosurgery with WBRT. The higher local control in SRS + WBRT may be interpreted as a proof of insufficiency of local treatment alone irrespective of how aggressive it is. Finally, a critical step in the follow-up management of patients treated with stereotactic radiosurgery for BM is the differentiation of a tumor recurrence from the radionecrosis [24][25].

It can be stated that - as anticipated - the addition of WBRT to local SRS treatment decreases the risk of an overall brain failure. An improvement in brain control with combined treatment is consistent with the results of other representative trials which compare whatever local treatment alone to a combination with WBRT [12]. The most important trials are summarized in table 2 and in many recent reviews [11][26]. Historically, the brain control seems to be the most important factor for the stabilization of the neurocognitive function, even though evaluation of the QoL and neurocognitive func- tion were in Aoyama's study reported only as an assessment of the systemic functional status by using the Karnofsky performance status score and the evaluation of neurologic functions [15][27].

Moving to recent years, the main concern regarding the inclusion of WBRT to the treatment of oligometastatic patients is the potential neurocognitive morbidity negatively influencing the quality of their remaining life. To address this concern, Chang et al. randomized patients after SRS of one to three brain metastases to undergo WBRT or observation, and evaluated the cognitive function as a primary endpoint (Hopkins Verbal Learning Test-Revised total recall at 4 months) [28]. This study was stopped before planned accrual according to early stopping criteria (predictable results) when significant worsening of the cognitive function was observed in the WBRT arm. Even though stopped earlier, these results should be considered a high level evidence supporting the omission of WBRT in upfront radiotherapy of patients with one to three brain metastases. Anyway, this seminal study published in 2009 accelerates the subsequent clinical investigation of iatrogenic side 
Table 2. Keynote clinical trials investigating local treatment \pm WBRT with PoF and survival characteristics

\begin{tabular}{|c|c|c|c|c|c|c|c|}
\hline \multirow{2}{*}{$\begin{array}{l}\text { Study and } \\
\text { reference }\end{array}$} & \multirow{2}{*}{$\begin{array}{c}\text { Number of } \\
\text { patients }\end{array}$} & \multirow[t]{2}{*}{ Treatment } & \multicolumn{3}{|c|}{ Patterns of failure } & \multirow[t]{2}{*}{ Median survival } & \multirow[t]{2}{*}{ Neurologic death } \\
\hline & & & Local failure & Distant failure & Overall failure & & \\
\hline \multirow{2}{*}{$\begin{array}{l}\text { Patchel et al., } \\
1998 \text { [8] }\end{array}$} & \multirow[t]{2}{*}{95} & $\mathrm{~S}$ & $46 \%$ & $37 \%$ & $70 \%$ & $43 \mathrm{w}$ & $44 \%$ \\
\hline & & $\mathrm{S}+\mathrm{WBRT}$ & $10 \%$ & $14 \%$ & $18 \%$ & $48 w$ & $14 \%$ \\
\hline \multirow{2}{*}{$\begin{array}{l}\text { Aoyama et al., } \\
2006 \text { [15] }\end{array}$} & \multirow[t]{2}{*}{132} & SRS & $27.5 \%$ & $63.7 \%$ & $76.4 \%$ & $8 \mathrm{mo}$ & $19.3 \%$ \\
\hline & & SRS + WBRT & $11.3 \%$ & $41.5 \%$ & $46.8 \%$ & $7.5 \mathrm{mo}$ & $22.8 \%$ \\
\hline \multirow{2}{*}{$\begin{array}{l}\text { Chang et al., } \\
2009 \text { [28] }\end{array}$} & \multirow[t]{2}{*}{58} & SRS & $33 \%$ & $55 \%$ & $73 \%$ & $15.2 \mathrm{mo}$ & $26.6 \%$ \\
\hline & & SRS + WBRT & 0 & $27 \%$ & $27 \%$ & $5.7 \mathrm{mo}$ & $25 \%$ \\
\hline \multirow{2}{*}{$\begin{array}{l}\text { Kocher et al., } \\
2011 \text { [12] }\end{array}$} & \multirow[t]{2}{*}{359} & S or SRS & $41 \%$ & $45 \%$ & $78 \%$ & $10.9 \mathrm{mo}$ & $44 \%$ \\
\hline & & S or SRS + WBRT & $21 \%$ & $28 \%$ & $48 \%$ & $10.7 \mathrm{mo}$ & $28 \%$ \\
\hline
\end{tabular}

S: surgery, SRS: stereotactic radiosurgery, w: weeks, mo: months

effects of brain irradiation. Nevertheless, it remains unclear, whether the omission of WBRT outweighs the lower overall brain control, which is probably the most important factor in a long-term cognitive stabilization.

Recently in July 2016, results of the North Central Cancer Treatment Group (NCCTG) (Alliance) N0574 study, a phase III trial with similar design to the Chang's study, were published in extenso. Cognitive deterioration at 3 months (primary outcome) was in the SRS + WBRT arm significantly higher compared to the SRS alone group in patients with 1-3 BM including patients with lung cancer. Based on these results, an initial treatment with SRS and close monitoring is recommended to better preserve the cognitive function in patients with newly diagnosed BM suitable for SRS [29]. As anticipated, intracranial tumor control rates were significantly better in patients with combined treatment. Furthermore, fewer patients underwent salvage therapy after SRS plus WBRT than after SRS alone $(7.8 \%$ vs $32.4 \%$, respectively, $\mathrm{p}<0.01)$. The difference was similar also in the cohort of long term survivals. Now, what is more important from patients' point of view - better intracranial control, or better cognitive function? The N0574 trial was powered to show the difference in neurocognitive status which is considered to be the most important factor for the best palliation. Nevertheless, a subsequent PoF analysis may provide an interesting future direction for the investigation of the role of combined SRS with HA-WBRT. Even if not specified within the planned secondary outcomes, the evaluation of PoF with respect to the hippocampal region may be interesting.

A similar recommendation favoring SRS alone to the combination of SRS + WBRT was drawn from a meta-analysis of individual patient data from randomized controlled trials evaluating SRS \pm WBRT in patients with one to four BM [30]. For patients $\leq 50$ years old, the median survival was 13.6 months in the SRS-alone comparing to 8.2 months in the SRS + WBRT arm. The PoF analysis revealed that the initial omission of WBRT did not impact the distant brain relapse rates, which further enhances the recommendation of SRS alone as an upfront treatment in the younger patients. Nevertheless, presented data are criticized especially with respect to the low number of patients being $\leq 50$ years of age ( 68 out of 364 included patients) and the fact that it is an unplanned post hoc subset analysis [31]. Interestingly, these data are interpreted in a completely opposite sense enhancing the need of robust well designed randomized trials as is N0574 for valid treatment recommendations [31] [32].

\section{Patterns of failure after hippocampal sparing WBRT}

Considering morbidity of symptomatic brain recurrence, as well as morbidity of treatment itself, the most important outcome in the management of newly diagnosed BM [33] is currently the quality of life. Increasing evidence supports the investigation of hippocampal avoidance during WBRT in order to mitigate its neurotoxicity, and the combination of local treatment and HA WBRT may constitute a reasonable compromise leading to an excellent brain control while minimizing neurotoxicity related to WBRT.

The cognitive sequelae of brain irradiation have been discussed for the last two decades [33][34]. Many different approaches were investigated in order to mitigate the post treatment neurocognitive impairment. Apart from the protective effect of some drugs [35], the main attention is paid to adjustments in radiotherapy delivery. Both experimental and preclinical data support the concept of HA during brain irradiation in order to prevent possible post-radiation neurocognitive impairment [36][37]. With the technological development and wider availability of advanced radiotherapy facilities, it is now technically feasible to spare hippocampus during partial, as well as whole brain radiotherapy [38][2][39]. The superiority of this approach has been recently confirmed by results of RTOG 0933, the first randomized trial (phase II) employing prospective HA. The mean relative decline of verbal memory, as the most commonly affected cognitive function, 
was significantly lower in the HA treatment approach compared to historical controls (7\% decline vs. 30\%, $\mathrm{p}<0.001)$ [40]. Safety profile for this study and for subsequent ongoing phase III trials depends on the PoF prediction.

One of the main concerns about accepting the HA-based radiotherapy is a potential undertreatment of spared parts of the brain, which may cause a potentially higher risk of later progression in this region. Based on the previously discussed studies about combination of local treatment and WBRT, it can be assumed, that the risk (probability) of a post-treatment recurrence within hippocampus pursues the same patterns as at the time of the first diagnosis. Patterns of BM in the spatial relationship to hippocampus revealed and confirmed safety of sparing this region while providing brain irradiation. On average, a minimum of brain metastasis is deposited in hippocampus itself and only a limited number is within $5 \mathrm{~mm}$ margin from hippocampus. This $5 \mathrm{~mm}$ is a typical volume enlargement to create such volume of hippocampal planningorgan-at-risk that enables a dose gradient fallout from the surrounding brain irradiated to the full prescribed dose. The most complex trials investigating the incidence of $\mathrm{BM}$ within hippocampus are summarized in Table 3.

In the summary of presented studies, the total of $7021 \mathrm{BM}$ was evaluated in 1557 patients. Despite the fact that not all authors reported the number of metastases within HA zone (hippocampus $+5 \mathrm{~mm}$ expansion), it can be concluded, that only $2.8 \%$ of all metastases developed within this region while only $0.6 \%$ metastases developed within the hippocampus itself. More important is the number of patients with a risk of hippocampal failure, because this information is more valuable from the patient's point of view during a decision-making process. The evaluation of patterns of BM from pooled data revealed that 87 out of 962 patients $(9 \%)$ had reported metastases within HA zone, while only 23 out of 1450 patients (1.6\%) had reported metastases within the hippocampus itself.

Post $\mathrm{HA}$ radiotherapy patterns of $\mathrm{BM}$ failure would perhaps follow similar probability. In accordance with the safety profile of recent ongoing trials of different HA radiotherapy approaches, it can be concluded that thanks to the evaluation of BM patterns, it is possible to proceed with phase III clinical trials with a promising expectation of further care improvement for BM patients. This is especially true for oligometastatic patients compared to patients with a higher number of present $B M$. The selection of patients for advanced radiotherapy techniques is of crucial importance in relation to cost effectiveness as well, and is enabled by many available prognosis estimators [48]. This is important especially for centers with limited availability of modern machines. For example, in a department equiped only with one machine enabling intensity modulated arc therapy who deserves priority on waiting list - a patient with currative radiotherapy for prostate cancer or a patient with limited brain metastases indicated for HA WBRT or SRS?

A future research in HA-based brain irradiation may be further influenced also by PoF analyses in relation to the laterality of involved hippocampus. Increasing evidence is supporting the hypothesis of separated hippocampal radio-injury of the most important cognitive domains [49][50].

\section{Conclusion}

Spatial patterns of a failure analysis after the brain metastases radiotherapy is a powerful tool for evaluating and revealing additional perspectives on different radiotherapy approaches. Apart from survival parameters, a local and distal brain control is a paramount outcome of local treatment of brain metastases including neurosurgery of stereotactic radiotherapy. Patterns of metastases failure after the local-only treatment can provide evidence for subsequent whole brain irradiation to be established as a standard treatment method in selected patients. Moreover, the knowledge of patterns of failure after different treatment strategies may predict outcomes of this treatment in terms of local or distant brain control. Currently, a combination of surgery with post-resection focal stereotactic radiotherapy is being investigated and patterns

Table 3. Summary of studies focusing on patterns of brain metastases

\begin{tabular}{|c|c|c|c|c|c|}
\hline \multirow[t]{2}{*}{ Study and reference } & \multirow[t]{2}{*}{ Patients / metastases } & \multicolumn{2}{|c|}{ Number of patients with metastasis } & \multicolumn{2}{|c|}{ Number of metastases } \\
\hline & & within $\mathrm{H}$ & within HA zone & within $\mathrm{H}$ & within HA zone \\
\hline Ghia et al., 2007 [41] & $100 / 272$ & 0 & $8(8 \%)$ & 0 & $9(3.3 \%)$ \\
\hline Marsh et al., 2010 [42] & $107 / 697$ & $1 / 53(1.9 \%)$ oligomet.pts & - & $16(2.29 \%)$ & - \\
\hline Gondi et al., 2010 [43] & $371 / 1133$ & 0 & $32(8.6 \%)$ & 0 & $34(3.0 \%)$ \\
\hline Wan et al., 2013 [44] & $488 / 2270$ & $7(1.4 \%)$ & - & $7(0.3 \%)$ & - \\
\hline Harth et al., 2013 [45] & $100 / 856$ & $3(3 \%)$ & $8(8 \%)$ & $3(0.4 \%)$ & $8(0.9 \%)$ \\
\hline $\begin{array}{l}\text { Hong et al., } 2014 \text { [46] } \\
\text { (melanoma patients) }\end{array}$ & $77 / 115$ & 0 & $4(5.2 \%)$ & 0 & $4(3.4 \%)$ \\
\hline $\begin{array}{c}\text { Sun et al., } 2016 \text { [47] } \\
\text { (breast ca patients) }\end{array}$ & $314 / 1678$ & $13(4.1 \%)$ & $35(11.1 \%)$ & $20(1.2 \%)$ & $59(3.5 \%)$ \\
\hline Sum of available data* & $1557 / 7021$ & $23 / 1450$ pts. (1.6\%) & $87 / 962(9 \%)$ & $46 / 7021(0.6 \%)$ & $114 / 4054(2.8 \%)$ \\
\hline
\end{tabular}


of failure analyses will provide key information about the superiority of such approach. Other useful information for predicting daily radiotherapy planning strategy may be provided by a dosimetrically detailed analysis of PoF, for example a categorization based on the received dose within the relapse region. Patterns of failure after hippocampus avoiding WBRT are also important for the prediction of possible failure within spared region of the brain, and thus it is necessary to consider pros and cons of this developing technique in a personalized approach in palliative care.

It may be concluded that a detailed dosimetrical analysis of patterns of failure and the evaluation of their topographics and time features in relation to survival characteristics should be a standard part of all ongoing clinical trials investigating different radiotherapy management of brain metastases.

Acknowledgements: This work was supported by grant MH CZ - RVO (MMCI, 00209805)

\section{References}

[1] DUSEK L, PAVLIK T, MAJEK O, BUCHLER T, MUZIK J et al. Estimating cancer incidence, prevalence, and the number of cancer patients treated with antitumor therapy in 2015 and 2020 - analysis of the Czech National Cancer Registry. Klin Onkol 2015; 28: 30-43. https://doi.org/10.14735/ amko201530

[2] KAZDA T, JANCALEK R, POSPISIL P, SEVELA O, PROCHAZKA $T$ et al. Why and how to spare the hippocampus during brain radiotherapy: the developing role of hippocampal avoidance in cranial radiotherapy. Radiat Oncol 2014; 9: 139. https://doi.org/10.1186/1748-717X-9-139

[3 ] LIN NU, LEE EQ, AOYAMA H, BARANI IJ, BARBORIAK DP et al. Response assessment criteria for brain metastases: proposal from the RANO group. Lancet Oncol 2015; 16:e270-278. https://doi.org/10.1016/S1470-2045(15)70057-4

[4 ] MiNNITI G, AMELIO D, AMICHETTI M, SALVATI M, MUNI R et al. Patterns of failure and comparison of different target volume delineations in patients with glioblastoma treated with conformal radiotherapy plus concomitant and adjuvant temozolomide. Radiother Oncol 2010; 97: 377-381. https://doi.org/10.1016/j.radonc.2010.08.020

[5 ] NIYAZI M, BRADA M, CHALMERS AJ, COMBS SE, ERRIDGE SC et al. ESTRO-ACROP guideline ,target delineation of glioblastomas." Radiother Oncol 2016; 118: 35-42. https:// doi.org/10.1016/j.radonc.2015.12.003

[6] TSAO MN, RADES D, WIRTH A, LO SS, DANIELSON $\mathrm{BD}$ et al. Radiotherapeutic and surgical management for newly dignosed brain metastasis(es): An American Society for Radiation Oncology evidence-based guidelines. Pract Radiat Oncol 2012; 2: 210-225. https://doi.org/10.1016/j. prro.2011.12.004

[7 ] RHUN EL, DHERMAIN F, NOEL G, REYNS N, CARPENTIER A et al. [ANOCEF guidelines for the management of brain metastases]. Cancer Radiother 2015; 19: 66-71. https:// doi.org/10.1016/j.canrad.2014.11.006
[8 ] PATCHELL RA, TIBBS PA, REGINE WF, DEMPSEY RJ, MOHIUDDIN $\mathrm{M}$ et al. Postoperative Radiotherapy in the Treatment of Single Metastases to the Brain. Jama 1998; 280: 1485-1489. https://doi.org/10.1001/jama.280.17.1485

[9 ] WALBERT T, KHAN M. End-of-life symptoms and care in patients with primary malignant brain tumors: a systematic literature review. J Neurooncol 2014; 117: 217-224. https:// doi.org/10.1007/s11060-014-1393-6

[10 ] NIEDER C, ASTNER ST, GROSU AL, ANDRATSCHKE $\mathrm{NH}$, MOLLS M. The role of postoperative radiotherapy after resection of a single brain metastasis. Combined analysis of 643 patients. Strahlenther Onkol 2007; 183: 576-580. https:// doi.org/10.1007/s00066-007-1756-4

[11] SOON YY, THAM IWK, LIM KH, KOH WY, LU JJ. Surgery or radiosurgery plus whole brain radiotherapy versus surgery or radiosurgery alone for brain metastases. Cochrane Database Syst Rev 2014; 3:CD009454. https://doi. org/10.1002/14651858.cd009454.pub2

[12 ] KOCHER M, SOFFIETTI R, ABACIOGLU U, VILLA S, FAUCHON F et al. Adjuvant whole-brain radiotherapy versus observation after radiosurgery or surgical resection of one to three cerebral metastases: results of the EORTC 22952-26001 study. J Clin Oncol 2011;29: 134-141. https://doi.org/10.1200/ JCO.2010.30.1655

[13 ] MEYERS CA, ROCK EP, FINE H et al. Refining endpoints in brain tumor clinical trials. J Neurooncol 2012; 108: 227-230. https://doi.org/10.1007/s11060-012-0813-8

[14 ] MEYERS CA, BROWN PD. Role and relevance of neurocognitive assessment in clinical trials of patients with CNS tumors. J Clin Oncol 2006; 24: 1305-1309. https://doi.org/10.1200/ LCO.2005.04.6086

[15 ] AOYAMA H, SHIRATO H, TAGO M, NAKAGAWA K, TOYODA T et al. Stereotactic Radiosurgery Plus Whole-Brain Radiation Therapy vs Stereotactic Radiosurgery Alone for Treatment of Brain Metastases. JAMA 2006; 295: 2483-2491. https://doi.org/10.1001/jama.295.21.2483

[16 ] JAGANNATHAN J, YEN CP, RAY DK, SCHLESINGER D, OSKOUIAN RJ et al. Gamma Knife radiosurgery to the surgical cavity following resection of brain metastases. J Neurosurg 2009; 111: 431-438. https://doi.org/10.3171/2008.11. INS08818

[17 ] KELLY PJ, LIN YB, YU AY, ALEXANDER BM, HACKER $\mathrm{F}$ et al. Stereotactic irradiation of the postoperative resection cavity for brain metastasis: a frameless linear acceleratorbased case series and review of the technique. Int J Radiat Oncol Biol Phys 2012; 82: 95-101. https://doi.org/10.1016/j. ijrobp.2010.10.043

[18 ] BROEMME J, ABU-ISA J, KOTTKE R, BECK J, WIEST R et al. Adjuvant therapy after resection of brain metastases. Frameless image-guided LINAC-based radiosurgery and stereotactic hypofractionated radiotherapy. Strahlenther Onkol 2013; 189: 765-770. https://doi.org/10.1007/s00066013-0409-Z

[19] ROBERGE D, PARNEY I, BROWN PD. Radiosurgery to the postoperative surgical cavity: who needs evidence? Int J Radiat Oncol Biol Phys 2012; 83: 486-493. https://doi.org/10.1016/j. ijrobp.2011.09.032 
[20 ] JARVIS LA, SIMMONS NE, BELLERIVE M, ERKMEN K, ESKEY CJ et al. Tumor bed dynamics after surgical resection of brain metastases: implications for postoperative radiosurgery. Int J Radiat Oncol Biol Phys 2012; 84: 943-948. https:// doi.org/10.1016/j.ijrobp.2012.01.067

[21 ] ATALAR B, CHOI CY, HARSH GR, CHANG SD, GIBBS IC et al. Cavity volume dynamics after resection of brain metastases and timing of postresection cavity stereotactic radiosurgery. Neurosurgery 2013; 72: 180-185. https://doi.org/10.1227/ NEU.0b013e31827b99f3

[22 ] CHOI CY, CHANG SD, GIBBS IC, ADLER JR, HARSH GR et al. Stereotactic radiosurgery of the postoperative resection cavity for brain metastases: prospective evaluation of target margin on tumor control. Int J Radiat Oncol Biol Phys 2012; 84: 336-342. https://doi.org/10.1016/j.ijrobp.2011.12.009

[23 ] THILLAYS F, DORÉ M, MARTIN SA. Postoperative brain radiotherapy: role of stereotactic radiotherapy. Cancer Radiother 2013; 17: 407-412. https://doi.org/10.1016/j.can$\underline{\operatorname{rad} .2013 .07 .134}$

[25 ] DOLEZELOVA H, HYNKOVA L, POSPISIL P, KAZDA T, SLAMPA $P$ et al. Therapeutic results of the treatment brain tumors using radiosurgery and stereotactic radiotherapy. Klin Onkol 2012; 25: 445-451.

[26 ] SCOCCIANTI S, RICARDI U. Treatment of brain metastases: review of phase III randomized controlled trials. Radiother Oncol 2012; 102: 168-179. https://doi.org/10.1016/j. radonc.2011.08.041

[27 ] AOYAMA H, TAGO M, KATO N, TOYODA T, KENJYO M et al. Neurocognitive function of patients with brain metastasis who received either whole brain radiotherapy plus stereotactic radiosurgery or radiosurgery alone. Int J Radiat Oncol Biol Phys 2007; 68: 1388-1395. https://doi.org/10.1016/j. ijrobp.2007.03.048

[28 ] CHANG EL, WEFEL JS, HESS KR, ALLEN PK, LANG FF et al. Neurocognition in patients with brain metastases treated with radiosurgery or radiosurgery plus whole-brain irradiation: a randomised controlled trial. Lancet Oncol 2009; 10: 1037-1044. https://doi.org/10.1016/S1470-2045(09)70263-3

[29 ] BROWN PD, JAECKLE K, BALLMAN KV, FARACE E, CERHAN JH et al. Effect of Radiosurgery Alone vs Radiosurgery With Whole Brain Radiation Therapy on Cognitive Function in Patients With 1 to 3 Brain Metastases: A Randomized Clinical Trial. JAMA 2016; 316: 401-409. https://doi.org/10.1001/ jama.2016.9839

[30 ] SAHGAL A, AOYAMA H, KOCHER M, NEUPANE B, COLLETTE $S$ et al. Phase 3 Trials of Stereotactic Radiosurgery With or Without Whole-Brain Radiation Therapy for 1 to 4 Brain Metastases: Individual Patient Data Meta-Analysis. Int J Radiat Oncol 2015; 91: 710-717. https://doi.org/10.1016/j. ijrobp.2014.10.024

[31 ] MEHTA MP. The controversy surrounding the use of wholebrain radiotherapy in brain metastases patients. Neuro Oncol 2015; 17: 919-923. https://doi.org/10.1093/neuonc/nov089

[32 ] SAHGAL A. Stereotactic radiosurgery without whole-brain radiation for patients with a limited number of brain metastases: the current standard of care? Neuro Oncol 2015; 17: 916-918. https://doi.org/10.1093/neuonc/nov087
[33 ] LAACK NN, BROWN PD. Cognitive sequelae of brain radiation in adults. Semin Oncol 2004; 31: 702-713. https://doi. org/10.1053/j.seminoncol.2004.07.013

[34 ] TAPHOORN MJ, SCHIPHORST AK, SNOEK FJ, LINDEBOOM J, WOLBERS JG, et al. Cognitive functions and quality of life in patients with low-grade gliomas: the impact of radiotherapy. Ann Neurol 1994; 36: 48-54. https://doi. org/10.1002/ana.410360111

[35 ] BROWN PD, PUGH S, LAACK NN, WEFEL JS, KHUNTIA D et al. Memantine for the prevention of cognitive dysfunction in patients receiving whole-brain radiotherapy: a randomized, double-blind, placebo-controlled trial. Neuro Oncol 2013; 15: 1429-1437. https://doi.org/10.1093/neuonc/ $\underline{\text { not114 }}$

[36] GREENE-SCHLOESSER D, ROBBINS ME, PEIFFER AM, SHAW EG, WHEELER KT, et al. Radiation-induced brain injury: A review. Front Oncol 2012; 2: 73. https://doi. org/10.3389/fonc.2012.00073

[37 ] GONDI V, TOME WA, MEHTA MP. Why avoid the hippocampus? A comprehensive review. Radiother Oncol 2010; 97: 370-376. https://doi.org/10.1016/j.radonc.2010.09.013

[38 ] GONDI V, TOLAKANAHALLI R, MEHTA MP, TEWATIA D, ROWLEY H et al. Hippocampal-sparing whole-brain radiotherapy: a „how-to" technique using helical tomotherapy and linear accelerator-based intensity-modulated radiotherapy. Int J Radiat Oncol Biol Phys 2010; 78: 1244-1252. https://doi. org/10.1016/j.ijrobp.2010.01.039

[39] TRUC G, MARTIN E, MIRJOLET C, CHAMOIS J, PETITFILS A et al. The role of whole brain radiotherapy with hippocampal-sparing. Cancer Radiother 2013; 17: 419-423. https://doi.org/10.1016/j.canrad.2013.06.042

[40 ] GONDI V, PUGH SL, TOME WA, CAINE C, CORN B et al. Preservation of Memory With Conformal Avoidance of the Hippocampal Neural Stem-Cell Compartment During Whole-Brain Radiotherapy for Brain Metastases (RTOG 0933): A Phase II Multi-Institutional Trial. J Clin Oncol 2014; 32: 3810-3816. https://doi.org/10.1200/JCO.2014.57.2909

[41 ] GHIA A, TOME WA, THOMAS S, CANNON G, KHUNTIA $\mathrm{D}$ et al. Distribution of brain metastases in relation to the hippocampus: implications for neurocognitive functional preservation. Int J Radiat Oncol Biol Phys 2007; 68: 971-977. https://doi.org/10.1016/j.ijrobp.2007.02.016

[42 ] MARSH JC, HERSKOVIC AM, GIELDA BT, HUGHES FF, HOEPPNER $\mathrm{T}$ et al. Intracranial metastatic disease spares the limbic circuit: a review of 697 metastatic lesions in 107 patients. Int J Radiat Oncol Biol Phys 2010; 76: 504-512. https://doi.org/10.1016/j.ijrobp.2009.02.038

[43 ] GONDI V, TOME WA, MARSH J, STRUCK A, GHIA A et al. Estimated risk of perihippocampal disease progression after hippocampal avoidance during whole-brain radiotherapy: safety profile for RTOG 0933. Radiother Oncol 2010; 95: 327-331. https://doi.org/10.1016/j.radonc.2010.02.030

[44 ] WAN JF, ZHANG SJ, WANG L, ZHAO KL. Implications for preserving neural stem cells in whole brain radiotherapy and prophylactic cranial irradiation: a review of 2270 metastases in 488 patients. J Radiat Res 2013; 54: 285-291. https://doi. org/10.1093/jrr/rrs085 
[45 ] HARTH S, ABO-MADYAN Y, ZHENG L, SIEBENLIST K, HERSKIND $\mathrm{C}$ et al. Estimation of intracranial failure risk following hippocampal-sparing whole brain radiotherapy. Radiother Oncol 2013; 109: 152-158. https://doi.org/10.1016/j. radonc.2013.09.009

[46 ] HONG AM, SUO C, VALENZUELA M, HAYDU LE, JACOBSEN KD et al. Low incidence of melanoma brain metastasis in the hippocampus. Radiother Oncol 2014; 111: 59-62. https://doi.org/10.1016/j.radonc.2014.01.012

[47 ] SUN B, HUANG Z, WU S, SHEN G, CHA L et al. Incidence and relapse risk of intracranial metastases within the perihippocampal region in 314 patients with breast cancer. Radiother Oncol 2016; 118: 181-186. https://doi.org/10.1016/j.radonc.2015.11.010

[48 ] KAZDA T, KUKLOVA A, POSPISIL P, BURKON P, SLAVIK $\mathrm{M}$ et al. Utilization of Prognostic Indexes for Patients with
Brain Metastases in Daily Radiotherapy Routine - is the Complexity and Intricacy Still an Issue? Klin Onkol 2015; 28: 352-358. https://doi.org/10.14735/amko2015352

[49 ] FARJAM R, PRAMANIK P, ARYAL MP, SRINIVASAN A, CHAPMAN CH et al. A Radiation-Induced Hippocampal Vascular Injury Surrogate Marker Predicts Late Neurocognitive Dysfunction. Int J Radiat Oncol 2015; 93: 908-915. https:// doi.org/10.1016/j.ijrobp.2015.08.014

[50 ] POSPISIL P, KAZDA T, HYNKOVA L, BULIK M, DOBIASKOVA $M$, et al. Post-WBRT cognitive impairment and hippocampal neuronal depletion measured by in vivo metabolic MR spectroscopy: Results of prospective investigational study. Radiother Oncol. 2017; 122: 373-379. https:// doi.org/10.1016/j.radonc.2016.12.013 